\title{
The endangered Brown Shrike subspecies Lanius cristatus superciliosus has a male-biased sex ratio and only early arriving males are paired
}

\author{
HARUKA MIZUMURA ${ }^{1 *}$ (D), KOHEI KUBOTA ${ }^{1}$ (D) and HIROYOSHI HIGUCHI ${ }^{2}$ (D) \\ ${ }^{1}$ Laboratory of Forest Zoology, Graduate School of Agricultural and Life Sciences, The University \\ of Tokyo, 1-1-1, Yayoi, Bunkyo-ku, Tokyo 113-8657, Japan. \\ ${ }^{2}$ Research and Education Center for Natural Sciences, Keio University, 4-1-1, Hiyoshi, Yokohama, \\ Kanagawa 223-8521, Japan.
}

*Author for correspondence; email: 249rugia.goshawk@gmail.com

(Received 15 October 2020; revision accepted 05 May 2021)

\section{Summary}

Along with many long-distance migrant passerine species in the East Asian-Australasian Flyway, the migratory Brown Shrike Lanius cristatus superciliosus has been sharply declining throughout its breeding range. Its breeding range in Japan shrank by $90.9 \%$ between the 1910s and 2010 . In contrast, the closely related but resident Bull-headed Shrike L. bucephalus bucephalus has been gradually declining but is still a common resident in Japan. To better understand the drastic decline of Brown Shrike, we compared the pairing success during three consecutive breeding seasons of these two species. About $60-70 \%$ of Brown Shrike males were unpaired, which was much higher than the percentage of unpaired male Bull-headed Shrike (c.O-20\%). Brown Shrike males arriving later did not pair because the population's sex proportion is heavily biased toward males. One of the factors of male-biased population of Brown Shrike may be female-biased mortality in wintering sites, or on the migratory journey, and tracking studies will be required to test this.

Keywords: arrival timing, migration, shrike conservation, male-biased sex ratio

\section{Introduction}

The East Asian-Australasian Flyway (EAAF), stretching from the Russian tundra to New Zealand's coasts (BirdLife International 2010), is one of the four globally recognized flyways and encompasses a greater number of threatened migratory bird species than any other flyway (Yong et al. 2015). Recent studies have demonstrated that populations of many songbirds such as buntings and shrikes that use the EAAF have undergone substantial declines during the past several decades (Amano and Yamaura 2007, Yamaura et al. 2009, Kamp et al. 2015, Edenius et al. 2017, Tamada et al. 2017, Choi et al. 2020) due to threats such as deforestation, agricultural expansion, and illegal trapping (Yong et al. 2015).

Biased sex ratios are common in birds but are more common in globally threatened species than in non-threatened species (Dale 200I, Donald 2007). The shortage of females reduces breeding success of the population through mating failure. Where there are many unpaired males in an endangered species, these populations become susceptible to environmental and demographic 
stochasticity (e.g. fluctuations in climate, habitat conditions, and random variation in sex ratio), and genetic degradation (e.g. inbreeding effects) (Lande 1993, 1995, Dale 2001), which can be critical for endangered species (e.g. Steifetten and Dale 2006).

The timing of arrival of long-distance migrants may also affect biased sex ratios. Early arrival allows for access to high-quality territories, which should help males attract healthier and/or more females (Aebischer et al. 1996), in turn increasing male reproductive fitness through better resources and earlier pairing (Potti 1998). Therefore, the timing of arrival is an important factor of the pairing process. After males arrive at the breeding ground, they establish territories and females arrive to choose a mate. A few males pair early in the breeding season, but the rest pair later and the number of unpaired males decrease. It is predicted that if the population sex ratio is biased toward males, only early arriving males will mate with a female.

In populations of Afro-Palearctic birds, declines are more sustained and severe in migrants than in resident birds, although migratory strategy and wintering area are important determinants as to the nature of any population change. (Sanderson et al. 2006, Ockendon et al. 2012). This trend also applies to the EAAF. In mature forest and early successional forest, the range sizes of long-distance migrants decreased more severely than those of short-distance migrants and residents (Yamaura et al. 2009). Thus, comparing pairing success between resident and migrant groups is important to assessing population trends, detecting factors that causes declines in population, and deciding on a conservation plan for migrant birds. Brown Shrike Lanius cristatus is a long-distance migrant that uses EAAF (Lefranc and Worfolk 1997, Yosef and International Shrike Working Group [ISWG] 2020). This species comprises four subspecies that typically overwinter in South-east Asia and breed over a large range in eastern Eurasia (Lefranc and Worfolk 1997, Yosef and International Shrike Working Group 2020). Brown Shrike are currently classified as 'Least Concern' on the IUCN Red List (BirdLife International 2016). However, a subspecies of Brown Shrike, L. c. superciliosus that typically breeds in Japan has been declining sharply over the past several decades and is classified as endangered (EN) in Japan (Biodiversity Center of Japan 2004, Ministry of the Environment 2020). Its breeding range contracted by $90.9 \%$ between the 1910s and 2010 (Kitazawa et al. in press). Nonetheless, the cause of this population decline has not yet been studied, and there are currently no conservation efforts to slow or reverse this decline.

The closely related Bull-headed Shrike L. bucephalus is also classified as 'Least Concern' on the IUCN Red List (BirdLife International 2017). Two subspecies of Bull-headed Shrike breed in eastern Asia: L. b. bucephalus, which is common, widespread, and typically breeds in Japan (Biodiversity Center of Japan 2004). It is a resident except at high altitudes (Ornithological Society of Japan 2012). The breeding ranges of Bull-headed and Brown Shrike overlap in Japan. These two species also have similar diets, habitat, and breeding ecology (i.e. they are territorial, social monogamists, open-cup nesters, and insectivorous) (Ishigaki 1966, Haneda and Takahashi 1968, Higuchi et al. 1997).

To determine the factors causing the decline in population of Brown Shrike, we studied the pairing process of Brown and Bull-headed Shrikes. We studied the sex ratio of the two shrike species and investigated whether the proportion of unpaired males would differ temporally between the species, whether unpaired males would be greater in endangered Brown Shrikes than in common Bull-headed Shrikes, and whether Brown Shrike males that arrive later would not pair with a mate.

\section{Methods}

The study site was on the northern foot of Mt. Fuji in Japan (720 ha, 900-1,100 m above sea level; Figure $\mathrm{S}_{1}$ in the online supplementary material), where both shrike species breed, and the Brown Shrike population is sharply declining. The site is a gentle slope on the skirts of Mt. Fuji, including a mosaic of farmland (mainly pastures), artificial structures (houses, stables, and a photovoltaic power plant), deserted arable land, and woodlands. The Bull-headed Shrike population included 
both residents and migrants (short distance) and initiated breeding in March (H. Mizumura unpubl. data). The Brown Shrike population began breeding in early to mid-May.

The roadside surveys occurred from mid-April to late July in 2017 ( 25 days), early April to late July in 2018 ( 25 days), and early May to late July in 2019 (nine days). The 2019 observation period was short because we only surveyed Brown Shrike. We travelled by car at low speeds $(<10 \mathrm{~km} / \mathrm{h})$ to search for probable shrike habitats using binoculars and telescopes for $2-3 \mathrm{~h}$ in the morning and/or afternoon, two or three times per week (Figure $\mathrm{S}_{1}$ ). This method was used mainly for Bull-headed Shrike because they were widespread in the study site. When a shrike was found, its location and behaviour (fighting, displaying, chasing, perching, foraging, and singing) were recorded. The arrival date of each male was defined as the day when that individual was observed for the first time. Observing females was difficult because they spent most of their time in shrubs, so we recorded their arrival dates and number as approximations only. We recorded all individual locations with a GPS (GPSMAP, 64sc, Garmin, Olathe, KS, USA) and the geographica smartphone application. We caught birds using mist nets $(30 \times 30 \mathrm{~mm}$ mesh size, $3.5 \mathrm{~m}$ high, 6-12 m long) set up around nest sites. Brown Shrikes $(n=6)$ were banded with a unique combination of bicoloured plastic bands in 2018. This work was done with permission from the Japanese Ministry of the Environment.

To identify individual locations and behaviour of Brown Shrike, we mapped its territories within an 18.8 ha area of the study site (Figure $S_{1}$ ). Territory mapping was carried out for $2 \mathrm{~h}$ in the morning at least once a week, from mid-April to late July in 2017, early April to late July in 2018, and early May to late July in 2019. Territory mapping is a highly accurate method of estimating breeding pairs in species that defend territories through singing, including shrikes (Gregory et al. 2004). We estimated the number of unpaired males and seasonal changes by mapping male territorial behavior (fighting, chasing, and singing) from April to July and approximating each territory. We confirmed a pairing when a male or a female was observed displaying, courtship feeding, nest building, with fledglings, or alarm calling. All records of Bull-headed Shrike were made by roadside surveys. The records of Brown Shrike in 2017 were made by only territory mapping, and those in 2018 and 2019 by both methods. Then we divided the survey season into sections: April, early May, mid-May, late May, early June, mid-June, late June, and July. "Early," "mid," and "late" indicate the 1st-1oth, 11th-2oth, and 21st-3oth or 31 st of each month, respectively.

Each day we counted the number of unpaired males and the total number of males and pairs to calculate the daily proportion of unpaired males (Tables $S_{1}, S_{2}$ and $S_{3}$ ). We also calculated the average proportion of unpaired males each season. To avoid overlap when counting territories, after the first record of a territory and pairing, we only recorded if there was a change in status of the focal pair or territory. Thus, once we recorded the territory of an unpaired male, only a newly formed territory of another male would be noted. When an unpaired male found a mate, we updated his status from "unpaired male" to "paired" only once. Therefore, we did not distinguish between first and second breeding attempts or breeding failures. We calculated the proportion of unpaired males during the breeding season using the number of unpaired males between April and July and the total number of males and females.

Locations of Brown and Bull-headed Shrikes were mapped with ArcGIS 10.6 (ESRI). We performed Wilcoxon rank-sum tests to examine the relationship between arrival order and paired or unpaired Brown Shrike males. We used chi-square tests to compare the proportions of unpaired males (in 2017 and 2018) between species. All analyses were conducted with R 3.6.1 (R Core Team 2019). Some results are shown as mean \pm standard deviations.

\section{Results}

We observed 9, 19, and 17 Brown Shrike individuals in 2017, 2018, and 2019, and 151 and 148 Bullheaded Shrike individuals in 2017 and 2018, respectively. In April and early May, there were $\sim 60-80$ unpaired Bull-headed Shrike males (Figure I), and this proportion decreased with seasonal succession, in particular in June. However, the proportion of unpaired Brown Shrike males was 


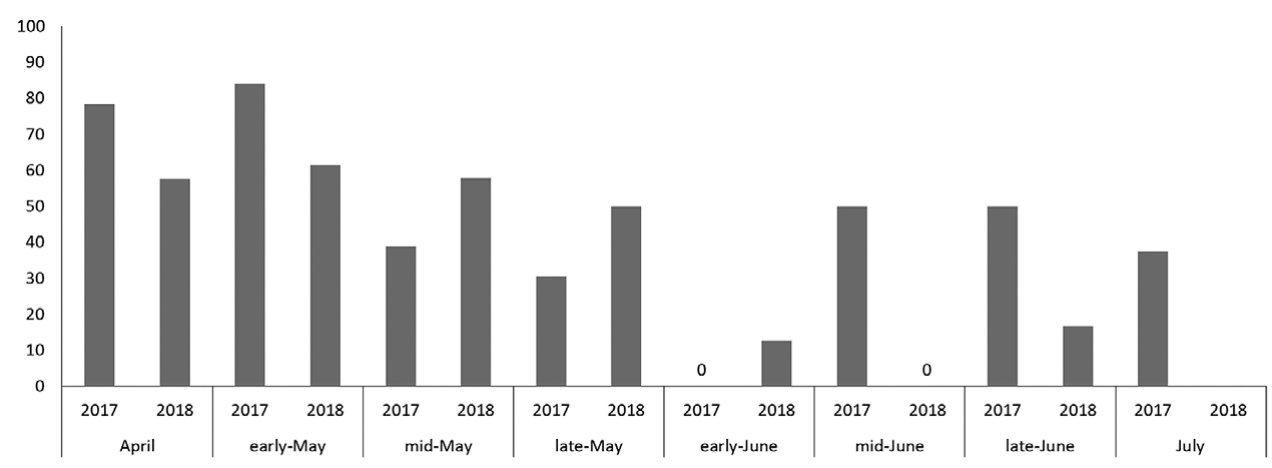

Figure 1. Seasonal change in the proportion of unpaired males for Bull-headed Shrike. "Early," "mid," and "late" indicate the 1st-1oth, 11th-2oth, and 21st-3oth or -31st of each month, respectively. All records of Bull-headed Shrike were given by roadside surveys (see Methods).

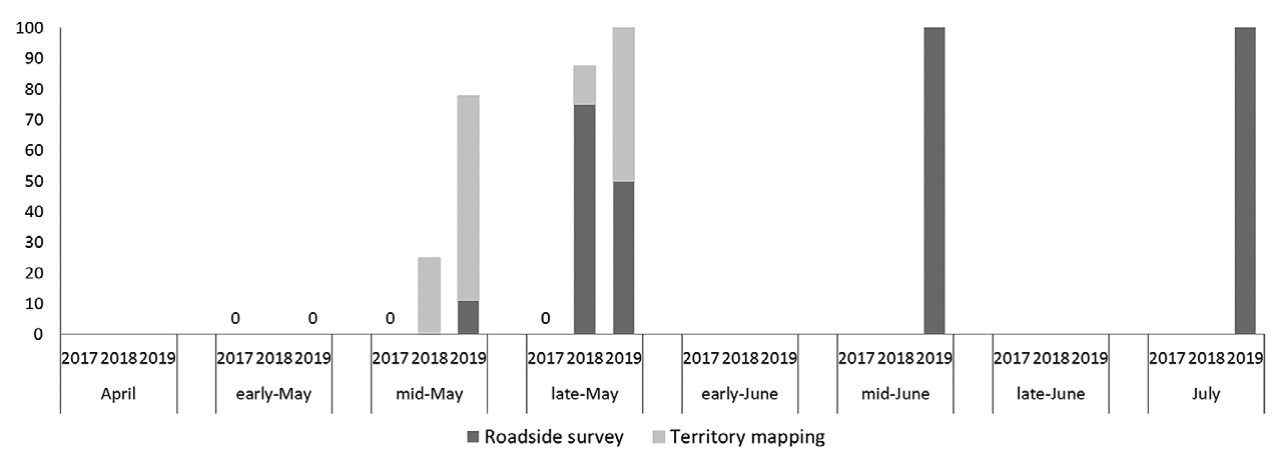

Figure 2. Seasonal change in the proportion of unpaired males for Brown Shrike. "Early," "mid," and "late" indicate the 1st-10th, 11th-20th, and 21st-3oth or -31st of each month, respectively. Dark grey shows the results of roadside survey, light grey shows the results of territory mapping (see Methods). Brown Shrike records in 2017 were given by only territory mapping, and those in 2018 and 2019 by both methods.

Table 1. Numbers of Brown Shrike breeding pairs and unpaired males (2017-2019) and Bull-headed Shrikes (2017-2018).

\begin{tabular}{lccccc}
\hline & Year & $\begin{array}{c}\text { Unpaired } \\
\text { male }\end{array}$ & Paired & $\begin{array}{c}\text { Total } \\
\text { male }\end{array}$ & $\begin{array}{c}\text { Percentage of unpaired } \\
\text { males }\end{array}$ \\
\hline Brown Shrike & 2017 & 1 & 4 & 5 & 20.0 \\
& 2018 & 9 & 5 & 14 & $64 \cdot 3$ \\
Bull-headed Shrike & 2019 & 9 & 4 & 13 & 69.2 \\
& 2017 & 15 & 62 & 77 & $19 \cdot 5$ \\
& 2018 & 0 & 83 & 83 & 0.0 \\
\hline
\end{tabular}

Unpaired males were counted during the breeding season.

lowest in early May and increased as the season progressed ( $>90 \%$ after mid-June; Figure 2$)$. The proportion of unpaired Brown Shrike males increased in $2018(64.3 \%, n=14)$ and $2019(69.2 \%$, $n=13)$. The proportion of unpaired Bull-headed Shrike males decreased from $2017(19.5 \%, n=77)$ to $2018(0 \%, n=83)$, when the total number of males increased (Table I). We recorded 74 and 


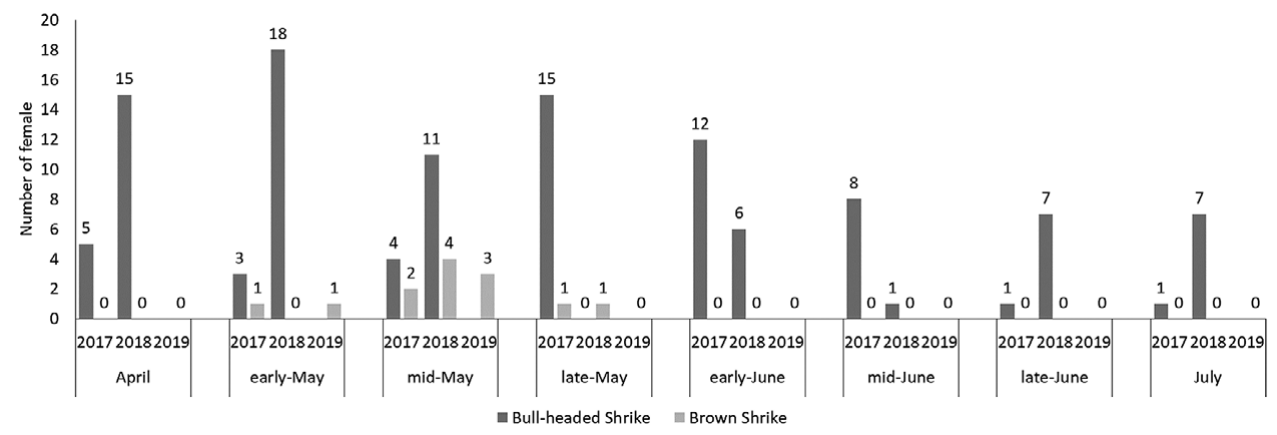

Figure 3. Seasonal change in the number of Bull-headed Shrike and Brown Shrike female recruitments. "Early," "mid," and "late" indicate the 1st-1oth, 11th-20th, and 21st-3oth or-31st of each month, respectively. Dark grey shows Bull-headed Shrikes, light grey shows Brown Shrikes. Brown Shrike records in 2017 were given by only territory mapping, and in 2018 and 2019 were given by roadside survey and territory mapping. All records of Bull-headed Shrike were given by roadside surveys from 2017 to 2018.

65 Bull-headed Shrike females in 2017 and 2018, respectively, and four, five, and four Brown Shrike females in 2017, 2018 and 2019, respectively. The proportion of unpaired Brown Shrike males was higher than that of Bull-headed Shrikes in 2017 and $2018\left(\chi^{2}=35.9, \mathrm{df}=1, P<0.001\right)$. Although the number of Brown Shrikes was lowest in 2017, the number of pairs was similar among years (2017: four pairs, 2018: five pairs, 2019: four pairs).

Brown Shrike males that arrived at the breeding sites earlier were more likely to pair and to breed, except in 2017. The paired males $(n=13)$ arrived approximately nine days earlier (May $16 \pm$ 5.62 days) than the unpaired males $(n=19$; May $25 \pm 13.6$ days, Wilcoxon rank sum test, $W=36$, $P<0.001)$. In 2017, few Brown Shrikes arrived at the study site, and most males paired. However, there were twice as many unpaired males in 2018 and 2019 as there were paired males. These unpaired males almost always arrived after May 20. The arriving peak of Brown Shrike female was in mid-May, and no females appeared after May. (Figure 3). All the Brown Shrike females had already paired in early stages (mainly mid-May) of the breeding season, just after arrival. However, Bull-headed Shrike females appeared from April to July, longer than those of Brown Shrike (Figure 3).

\section{Discussion}

The number of unpaired Bull-headed Shrike males gradually decreased within each breeding season. In the Brown Shrike, those that arrived early in the breeding season paired, while the majority of males arriving later remained unpaired. As a result, approximately $60-70 \%$ of Brown Shrike males remained unpaired throughout the breeding season. The sex ratio was heavily malebiased in Brown Shrike, and the later arrivals could not pair because females were in short supply, and all the females had already paired. In this context, it is impressive that each of two banded males paired in 2018, but they did not pair in the following year when their arrival dates were about 1o days later than in 2018. Their territory in 2019 was nearby their 2018 territory, but another male had already occupied their former territory when the banded males arrived.

The male-biased sex ratio in the Brown Shrike population could be caused by (I) females tending to disperse further from natal breeding areas than males in many bird species, thus small and/or isolated populations tend to have lower female recruitment than large and/or not isolated populations, and (2) the greater mortality of females at some point in the life cycle. Donald (2007) indicates that female mortality is the main cause of skewed adult sex ratio in birds. Understanding 
the variation in biased sex ratios, and the drivers would provide insights for the management of species of high conservation concern (Bessa-Gomes et al. 2004, Donald 2007).

In terms of (I), Dale (200I) reported that small and isolated populations have a higher proportion of unpaired males (male-biased sex proportion) due to lower natal philopatry (tendency to return to a particular area) of females. The population of Brown Shrike is more isolated and smaller than that of Bull-headed Shrike in Japan (Biodiversity Center of Japan 2004, Kitazawa et al. in press) including this study site. Sexual bias in philopatry, with males returning more frequently, has been found in both shrike species (Takagi 2003). However, Brown Shrike female philopatry is greater than that of Bull-headed Shrikes (Takagi 2003). Thus, female-biased dispersal may not explain the male-biased proportion of the isolated Brown Shrike population. In terms of (2), there are two factors that contribute to female biased mortality in Brown Shrike. First is the risk of mortality during incubation by females (Dale 2001, Donald 2007). However, Brown Shrike and Bull-headed Shrike have similar incubation traits, and the female mostly does the incubation (Haneda and Takahashi 1968, Endo and Ueda 2016). The incubation periods are similar, lasting c.14 days in Brown Shrike (Haneda and Takahashi 1968) and 15 days in Bull-headed Shrike (Endo 2012). Therefore, the risk of female incubation is unlikely to have contributed to the male-biased sex ratio in Brown Shrike.

The second possibility is that males and females use different non-breeding habitats, and the female's habitat type has been destroyed and deteriorated (Bennett et al. 2019). Several studies have shown female-biased mortality and habitat loss over the non-breeding season or at wintering sites in some avian groups such as warblers and penguins (Vanstreels et al. 2013, Gownaris and Boersma 2019, Yamamoto et al. 2019, Bennett et al. 2019). However, there are no reports on sexual habitat segregation and female-biased mortality in the nonbreeding areas of Brown Shrikes. It is necessary to identify the migration routes, wintering sites and arriving timing in male and female Brown Shrikes using tracking devices such as geolocators or small archival GPS tags.

\section{Supplementary Materials}

To view supplementary material for this article, please visit http://doi.org/10.1017/ S0959270921000216.

\section{Acknowledgements}

Special thanks to Michihito Watanabe and Sadao Imanishi for the valuable advice and facilitation that made this work possible. We also thank the residents and farmers of survey sites. This study was supported by the Awai Hidero Environment Foundation (during 2017-2018).

\section{References}

Aebischer, A., Perrin, N., Krieg, M., Studer, J. and Meyer, D. R. (1996) The role of territory choice, mate choice and arrival date on breeding success in the Savi's Warbler Locustella luscinioides. J. Avian Biol. 27: 143-152.

Amano, T. and Yamaura, Y. (2007) Ecological and life-history traits related to range contractions among breeding birds in Japan. Biol. Conserv. 137: 271-282.

Bennett, R. E., Rodewald, A. D. and Rosenberg, K. V. (2019) Overlooked sexual segregation of habitats exposes female migratory landbirds to threats. Biol. Conserv. 240: 108266.

Bessa-Gomes, C., Legendre, S. and Clobert, J. (2004) Allee effects, mating systems and the extinction risk in populations with two sexes. Ecol. Lett. 7: 802-812.

Biodiversity Center of Japan (2004) The National Survey on the Natural Environment Report of the distributional survey of Japanese animals (Birds). Fujiyoshida, Japan: Nature Conservation Bureau, Ministry of the Environment. (In Japanese). 
BirdLife International (2010) Spotlight on flyways. http://datazone.birdlife.org/sowb/ spotFlyway Accessed on 22 December 2020.

BirdLife International (2016) Lanius cristatus. The IUCN Red List of threatened species 2016: e.T22705011A93995637. http://doi. org/10.2305/IUCN.UK.2016-3.RLTS.

T22705011A93995637.en. Accessed on 9 June 2020.

BirdLife International (2017) Lanius bucephalus (amended version of 2016 assessment). The IUCN Red List of Threatened Species 2017: e.T22704998A118773936. https://doi.org/10.2305/IUCN.UK.2017-3. RLTS.T22704998A118773936.en. Accessed on 9 June 2020.

Choi, C. Y., Nam, H. Y., Kim, H. K., Park, S. Y. and Park, J. G. (2O20) Changes in Emberiza bunting communities and populations spanning 100 years in Korea. PLoS ONE 15: e0233121.

Dale, S. (2001) Female-biased dispersal, low female recruitment, unpaired males, and the extinction of small and isolated bird populations. Oikos 92: 344-356.

Donald, P. F. (2007) Adult sex ratios in wild bird populations. Ibis 149: 671-692.

Edenius, L., Choi, C. Y., Heim, W., Jaakkonen, T., Jong, A. D., Ozaki, K. and Roberge, J. M. (2017) The next common and widespread bunting to go? Global population decline in the Rustic Bunting Emberiza rustica. Bird Conserv. Internatn. 27: 35-44.

Endo, S. (2012) Nest-site characteristics affect probability of nest predation of Bull-headed Shrikes. Wilson J. Ornithol. 124: 513-517.

Endo, S. and Ueda, K. (2016) Factors affecting female incubation behavior in the Bullheaded Shrike. Ornithol. Sci. 15: 151-161.

Gownaris, N. J. and Boersma, P. D. (2019) Sexbiased survival contributes to population decline in a long-lived seabird, the Magellanic Penguin. Ecol. Applic. 29: e01826.

Gregory, R. D., Gibbons, D. W. and Donald, P. E. (2004) Bird census and survey techniques. Pp. $17-56$ in W. J. Sutherland, I. Newton, and R. E. Green, eds. Bird ecology and conservation: A handbook of techniques. Oxford: Oxford University Press.

Haneda, K. and Takahashi, Y. (1968) Life history of the Japanese Red-tailed Shrike (Lanius cristatus superciliosus) I. Breeding season. Japanese. J. Ecol. 18: 47-56. (In Japanese).

Higuchi, H., Morioka, H. and Yamagishi, S. (1997) The encyclopedia of animals in Japan. Volume 4: Birds 2. Tokyo: Heibonsha. (In Japanese).

Ishigaki, K. (1966) The interspecific territorialism between the Shrikes, Lanius bucephalus and L. cristatus in their cohabiting area. Japanese. J. Ecol. 16: 87-93. (In Japanese).

Kamp, J., Oppel, S., Ananin, A. A., Durnev, Y. A., Gashev, S. N., Hölzel, N., Mishchenko, A. L., Pessa, J., Smirenski, S. M., Strelnikov, E. G., Timonen, S., Wolanska, K. and Chan, S. (2015) Global population collapse in a superabundant migratory bird and illegal trapping in China. Conserv. Biol. 29: 1684-1694.

Kitazawa, M., Senzaki, M., Matsumiya, H., Hara, S. and Mizumura, H. (in press) Drastic decline in the endemic brown shrike subspecies Lanius cristatus superciliosus in Japan. Bird Conserv. Int. First View 1-9.

Lande, R. (1993) Risks of population extinction from demographic and environmental stochasticity and random catastrophes. Am. Nat. 142: 911-927.

Lande, R. (1995) Mutation and conservation. Conserv. Biol. 9: 782-791.

Lefranc, N. and Worfolk, T. (1997) Shrikes: a guide to the shrike of the world. Sussex, UK: Pica Press.

Ministry of the Environment (2020) Kankyosho Red List 2020 (Chourui). [Ministry of the Environment Red List 2020 (Aves)]. http:// www.env.go.jp/press/files/jp/II4457.pdf.

Accessed on 4 September 202O. (In Japanese).

Ockendon, N., Hewson, C. M., Johnston, A. and Atkinson, P. W. (2012) Declines in British-breeding populations of AfroPalaearctic migrant birds are linked to bioclimatic wintering zone in Africa, possibly via constraints on arrival time advancement. Bird Study 59: 111-125.

Ornithological Society of Japan (2012) Checklist of Japanese Birds. 7 th revised edition. Sanda: The Ornithological Society of Japan. (In Japanese).

Potti, J. (1998) Arrival time from spring migration in male Pied Flycatchers: Individual consistency and familial resemblance. Condor 100: 702-708. 
R Core Team (2019) R: A language and environment for statistical computing. Vienna, Austria: R Foundation for Statistical Computing. https://www.R-project.org/. Accessed on 9 June 2020.

Sanderson, F. J., Donald, P. F., Pain, D. J., Burfield, I. J. and van Bommel, F. P. J. (2006) Long-term population declines in Afro-Palearctic migrant birds. Biol. Conserv. 131: 93-105.

Steifetten, Ø. and Dale, S. (2006) Viability of an endangered population of ortolan buntings: The effect of a skewed operational sex ratio. Biol. Conserv. 132: 88-97.

Takagi, M. (2003) Philopatry and habitat selection in Bull-headed and Brown shrikes. J. Field Ornithol. 74: 45-52.

Tamada, K., Hayama, S., Umeki, M., Takada, M. and Tomizawa, M. (2017) Drastic declines in Brown Shrike and Yellowbreasted Bunting at the Lake Utonai Bird Sanctuary, Hokkaido. Ornithol. Sci. 16: $51-57$.

Vanstreels, R. E. T., Adornes, A. C., Canabarro, P. L., Ruoppolo, V., Amaku, M. and da SilvaFilho, R. P. and Catão-Dias, J. L. (2013)
Female-biased mortality of Magellanic Penguins Spheniscus magellanicus on the wintering grounds. Emu 113: 128-134.

Yamamoto, T., Yoda, K., Blanco, G. S. and Quintana, F. (2019) Female-biased stranding in Magellanic penguins. Current. Biol. 29: R12-R13.

Yamaura, Y., Amano, T., Koizumi, T., Mitsuda, Y., Taki, H. and Okabe, K. (2009) Does landuse change affect biodiversity dynamics at a macroecological scale? A case study of birds over the past 20 years in Japan. Anim. Conserv. 12: 110-119.

Yong, D. L., Liu, Y., Low, B. W., Española, C. P., Choi, C. Y. and Kawakami, K. (2015) Migratory songbirds in the East AsianAustralasian Flyway: a review from a conservation perspective. Bird Conserv. Int. 25: 1-37.

Yosef, R. and International Shrike Working Group (2020) Brown Shrike (Lanius cristatus), version 1.o. In J. del Hoyo, A. Elliott, J. Sargatal, D. A. Christie and E. de Juana, eds. Birds of the world. Ithaca: Cornell Lab of Ornithology. https://doi.org/10.2173/bow. brnshr.oI. 